\title{
The Use of Non-Ideality Parameters for the Analysis of Thermodynamic Properties of Binary Mixtures
}

\author{
Marcos Caroli Rezende, ${ }^{\mathrm{a},}{ }^{*}$ Vanderlei Gageiro Machado, b Simone Morales, a Matías \\ Vidal $^{\text {a }}$
}

\begin{abstract}
${ }^{a}$ Facultad de Química y Biología, Universidad de Santiago de Chile, Santiago, Chile
b Departamento de Química, Universidade Federal de Santa Catarina, Florianópolis, SC, Brasil
\end{abstract}




\section{CONTENTS}

Fitting equation and parameters

Table S1 - Parameters and correlation coefficients, according to Equation 1, for the

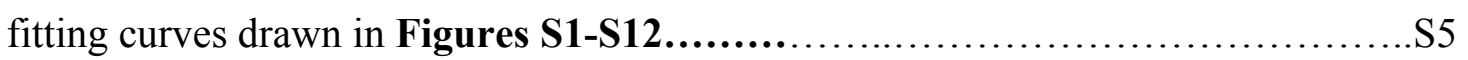

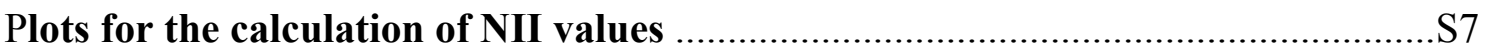

Figure S1 - Variations of densities for ROH/dimethylacetamide mixtures at 298.15K. ROH = 2-propanol (a), 2-butanol (b), 2-pentanol (c), 2-hexanol (d), 2-heptanol (e). S7

Figure S2 - Variations of densities for ROH/dimethylcarbonate mixtures at 298.15K. $\mathrm{ROH}$ = 2-propanol (a), 2-butanol (b), 2-pentanol (c), 2-hexanol (d), 2-heptanol (e).

Figure S3 - Variations of viscosities of 1-decanol/ROH mixtures at $15^{\circ} \mathrm{C} . \mathrm{ROH}=$ methanol (a), ethanol (b), 1-propanol (c), 1-butanol (d). S9

Figure S4 - Variations of viscosities of 1-decanol/methanol mixtures at $25^{\circ} \mathrm{C}\left(\right.$ a), $35^{\circ} \mathrm{C}$ (b), $45^{\circ} \mathrm{C}(\mathrm{c}), 55^{\circ} \mathrm{C}(\mathrm{d})$.

Figure S5 - Variations of densities of $\mathrm{ROH} / \mathrm{n}$-Butylammonium butanoate (BAB) mixtures at $298.15 \mathrm{~K} . \mathrm{ROH}$ = methanol (a), ethanol (b), 1-propanol (c), 1-butanol (d), 1pentanol(e)......

Figure S6 - Variations of viscosities of Methanol/[Bmim] $\mathrm{BF}_{4}$ mixtures at $278.15 \mathrm{~K}$ (a); $288.15 \mathrm{~K}$ (b); $298.15 \mathrm{~K}$ (c), $308.15 \mathrm{~K}$ (d), 318.15 K (e).

Figure S7 - Variations of viscosities of Methanol/[Emim] $] \mathrm{BF}_{4}$ mixtures at $278.15 \mathrm{~K}$ (a); $288.15 \mathrm{~K}$ (b); $298.15 \mathrm{~K}$ (c), 308.15 K (d), 318.15 K (e). $\mathrm{S} 13$

Figure S8 - Variations of densities of mixtures of fatty acid esters + methylcyclohexane $(\mathrm{MCH})$ at $298.15 \mathrm{~K}$. (a) Methyl decanoate / $\mathrm{MCH}$; (b) methyl dodecanoate/MCH; (c) methyl tetradecanoate/ $\mathrm{MCH}$. S14

Figure S9 - Variations of viscosities of methyl decanoate/methylcyclohexane mixtures at increasing temperatures. (a) $293.15 \mathrm{~K}$; (b) $303.15 \mathrm{~K}$; (c) $313.15 \mathrm{~K}$; (d) 323.15 $\mathrm{K}$. S15

Figure S10 - Variations of viscosity of 1-BuOH/Methyl acrylate mixtures at increasing temperatures. (a) $288.15 \mathrm{~K}$; (b) $298.15 \mathrm{~K}$; (c) $308.15 \mathrm{~K}$; (d) $318.15 \mathrm{~K}$. S16

Figure S11 - Variations of viscosity of 1-alkanol/methyl acrylate mixtures at $298.15 \mathrm{~K}$. (a) 1-hexanol/methyl acrylate; (b) 1-octanol/methyl acrylate; (c) 1-decanol/methyl acrylate. S17 
Figure S12 - Deviations of the refractive index at $298.15 \mathrm{~K}$ of aqueous solutions of organic solvents. (a) $\mathrm{H}_{2} \mathrm{O} / \mathrm{THF}$; (b) $\mathrm{H}_{2} \mathrm{O} / \mathrm{DMF}$; (c) $\mathrm{H}_{2} \mathrm{O} / \mathrm{DMSO}$;

$\mathrm{H}_{2} \mathrm{O}$ /Ethyleneglycol; (e) $\mathrm{H}_{2} \mathrm{O}$ /acetonitrile. S18

Fitting equation and parameters for excess properties S19

Table S2 - Parameters and correlation coefficients, according to Equation 2, for the fitting curves drawn in Figures S13-S17 S19

Plots for the calculation of NIA values S20

Figure S13 - Variations of excess enthalpies of arenes/dimethylsulfoxide mixtures at 298.15 K. Arene = benzene (a), toluene (b), ethylbenzene (c), 1-propylbenzene (d), 2propylbenzene (e), 1-butylbenzene (f), sec-butylbenzene (g), ter-butylbenzene (h).

S20

Figure S14 - Variations of excess enthalpies of polyhaloalkanes/dimethylsulfoxide mixtures at $298.15 \mathrm{~K}$. Polyhaloalkane = 1-chloropropane (a), 1-chlorobutane (b), 1chloropentane (c), 1-chlorohexane (d), tetrachloromethane (e), trichloromethane (f), 1,1,2,2-tetrachloroethane (g). S21

Figure S15 - Variations of excess molar volumes of ROH/n-butylammonium oleate $(\mathrm{BAO})$ mixtures at $298.15 \mathrm{~K}, \mathrm{ROH}=1$-propanol (a), 1-butanol (b), 1-pentanol (c), 1hexanol (d) . 222

Figure S16 - Variations of isentropic compressibilities of $\mathrm{ROH} / \mathrm{n}$-butylammonium oleate $(\mathrm{BAO})$ mixtures at $298.15 \mathrm{~K}, \mathrm{ROH}=1$-propanol (a), 1-butanol (b), 1-pentanol (c), 1-hexanol (d)... S22

Figure S17 - Variations of excess molar volumes of water/alcohols and water/polyethyleneglycol (PEG) mixtures at $298.15 \quad \mathrm{~K}$. (a) $\mathrm{H}_{2} \mathrm{O} / \mathrm{EtOH}$; (b) $\mathrm{H}_{2} \mathrm{O}$ /Glycerol; (c) $\mathrm{H}_{2} \mathrm{O}$ /Ethyleneglycol; (d) $\mathrm{H}_{2} \mathrm{O}$ /Diethyleneglycol; $\mathrm{H}_{2} \mathrm{O}$ /Triethyleneglycol; (f) $\mathrm{H}_{2} \mathrm{O} / \mathrm{PEG} 200$; (g) $\mathrm{H}_{2} \mathrm{O} / \mathrm{PEG} 300$; (h) $\mathrm{H}_{2} \mathrm{O} / \mathrm{PEG} 400$; (i)

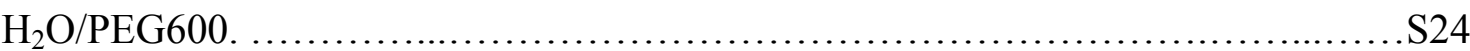

Detailed procedure for calculating NII or NIA values.......................... 25

Figure S18 - Examples of experimental plots (Figs. S5a and S7a) from which the nonideality index is calculated as the ratio between areas $\mathrm{S}$ and $\mathrm{S}_{\mathrm{ABC}}$. A positive sign is attributed to the value if the plot indicates a variation governed by the second, added component of the mixture [plot (a)]. A negative sign is attributed to the value if the plot indicates that the variation is governed by the first component [plot (b)]. Arrows point to the component which governs the property variation. S25 
Figure S19 - Examples of experimental plots (Figs. S14c and S14g) from which the non-ideality area (NIA) is calculated as the integrated area S under the fitting curve, between points A and B. Plots (a) and (b) correspond to positive and negative NIA

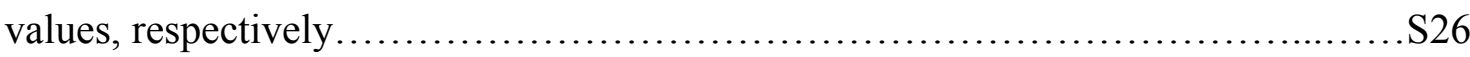

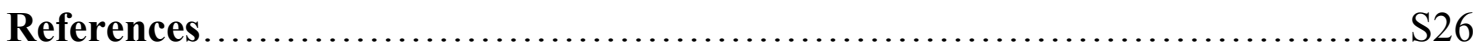




\section{Fitting equation and parameters}

Experimental data of plots of Figures S1-S12 were fitted with equation (1). Fitting parameters A, B, C and D are given in Table S1, together with the corresponding squared correlation coefficients.

$P-P_{1}=\Delta P=\left[\mathrm{AX}_{2}{ }^{2}+\mathrm{B}\left(1-\mathrm{X}_{2}\right) \mathrm{X}_{2}\right] /\left[\left(1-\mathrm{X}_{2}\right)^{2}+\mathrm{C} \mathrm{X}_{2}{ }^{2}+\mathrm{D}\left(1-\mathrm{X}_{2}\right) \mathrm{X}_{2}\right]$

Table S1 - Parameters and correlation coefficients, according to Equation 1, for the fitting curves drawn in Figures S1-S12

\begin{tabular}{|c|c|c|c|c|c|c|}
\hline Figure & A & B & $\mathrm{C}$ & D & $R^{2}$ & $\begin{array}{l}N(\text { Data } \\
\text { points })\end{array}$ \\
\hline S1a & 0.5 & 0.19 & 3.23 & 3.81 & 1 & 12 \\
\hline S1b & 0.75 & 0.13 & 5.61 & 6.91 & 1 & 12 \\
\hline S1c & 0.64 & 0.09 & 4.86 & 7.01 & 1 & 12 \\
\hline S1d & 0.12 & 0.08 & 0.94 & 2.05 & 1 & 12 \\
\hline S1e & 0.02 & 0.07 & 0.2 & 0.89 & 1 & 12 \\
\hline S2a & 0.18 & 0.29 & 0.62 & 1.65 & 1 & 12 \\
\hline $\mathbf{S 2 b}$ & 0.12 & 0.21 & 0.47 & 1.39 & 1 & 12 \\
\hline S2c & 1.34 & 0.17 & 5.22 & 8.25 & 1 & 12 \\
\hline S2d & 0.17 & 0.15 & 0.69 & 1.72 & 1 & 12 \\
\hline S2e & 0.095 & 0.13 & 0.38 & 1.22 & 1 & 12 \\
\hline S3a & -30.39 & -19.37 & 1.92 & 1.86 & 1 & 21 \\
\hline S3b & -25.19 & -18.44 & 1.66 & 1.94 & 1 & 21 \\
\hline S3c & -34.58 & -13.58 & 2.45 & 2.55 & 1 & 21 \\
\hline S3d & -40.99 & -13.24 & 3.09 & 3 & 1 & 21 \\
\hline S4a & -14.27 & -11.81 & 1.37 & 1.69 & 1 & 21 \\
\hline S4b & -6.38 & -7.39 & 0.91 & 1.51 & 1 & 21 \\
\hline S4c & -4.3 & -4.4 & 0.87 & 1.43 & 1 & 21 \\
\hline S4d & -40.33 & 5.23 & 11.05 & 7.29 & 1 & 21 \\
\hline S5a & 0.09 & 0.93 & 0.67 & 6.7 & 1 & 21 \\
\hline S5b & 0.0044 & 0.54 & 0.031 & 3.88 & 1 & 21 \\
\hline S5c & $5.70 \mathrm{E}-05$ & 0.35 & 0.0045 & 2.79 & 1 & 20 \\
\hline S5d & 0.031 & 0.26 & 0.26 & 2.34 & 1 & 22 \\
\hline S5e & 0.63 & 0.21 & 5.53 & 5.09 & 1 & 21 \\
\hline S6a & 23.63 & 5.49 & 0.07 & 0.42 & 1 & 15 \\
\hline S6b & 14.37 & 6.16 & 0.08 & 0.44 & 1 & 15 \\
\hline S6c & 10.06 & 5.51 & 0.1 & 0.48 & 1 & 15 \\
\hline S6d & 8.93 & 4.38 & 0.14 & 0.63 & 1 & 15 \\
\hline S6e & 7.45 & 3.7 & 0.18 & 0.72 & 1 & 15 \\
\hline $\mathbf{S 7 a}$ & 13.06 & 4.43 & 0.13 & 0.73 & 1 & 15 \\
\hline S7b & 10.34 & 3.73 & 0.17 & 0.82 & 1 & 15 \\
\hline S7c & 8.1 & 3.27 & 0.2 & 0.86 & 1 & 15 \\
\hline S7d & 6.89 & 2.75 & 0.24 & 0.92 & 1 & 15 \\
\hline S7e & 5.63 & 2.41 & 0.27 & 0.92 & 1 & 15 \\
\hline S8a & -0.02 & -0.06 & 0.15 & 0.85 & 1 & 11 \\
\hline
\end{tabular}




$\begin{array}{lllllll}\text { S8b } & -0.04 & -0.05 & 0.42 & 1.32 & 1 & 11 \\ \text { S8c } & -0.02 & -0.05 & 0.2 & 0.9 & 1 & 11 \\ \text { S9a } & -1.39 & -1.75 & 1.14 & 1.98 & 0.999 & 11 \\ \text { S9b } & -0.09 & -1.38 & 0.08 & 1.3 & 1 & 11 \\ \text { S9c } & -0.63 & -1.02 & 0.71 & 1.66 & 1 & 11 \\ \text { S9d } & -0.69 & -0.81 & 0.93 & 1.84 & 0.999 & 11 \\ \text { S10a } & -16.28 & -9.49 & 5.88 & 3.48 & 0.999 & 15 \\ \text { S10b } & -15.47 & -6.34 & 7.32 & 3.34 & 0.999 & 15 \\ \text { S10c } & -12.41 & -4.72 & 7.79 & 3.75 & 0.999 & 15 \\ \text { S10d } & -10.27 & -3.2 & 8.35 & 3.91 & 0.999 & 15 \\ \text { S11a } & -31.67 & -12.71 & 7.71 & 3.63 & 0.999 & 15 \\ \text { S11b } & -16.71 & -18.99 & 2.43 & 2.72 & 0.999 & 15 \\ \text { S11c } & -37.16 & -23.88 & 3.45 & 2.5 & 0.999 & 15 \\ \text { S12a } & 2.39 & 0.42 & 32.24 & 9.17 & 0.999 & 11 \\ \text { S12b } & 1.6 & 0.45 & 16.63 & 6.05 & 0.999 & 11 \\ \text { S12c } & 0.11 & 0.63 & 0.76 & 4.33 & 0.997 & 11 \\ \text { S12d } & 0.01 & 0.3 & 0.15 & 3.56 & 0.999 & 11 \\ \text { S12e } & 0.13 & 0.18 & 13.21 & 8.92 & 0.997 & 11\end{array}$




\section{Plots for the calculation of NII values}

All plots are original, and were drawn with fitting equation (1) and parameters listed in Table S1.
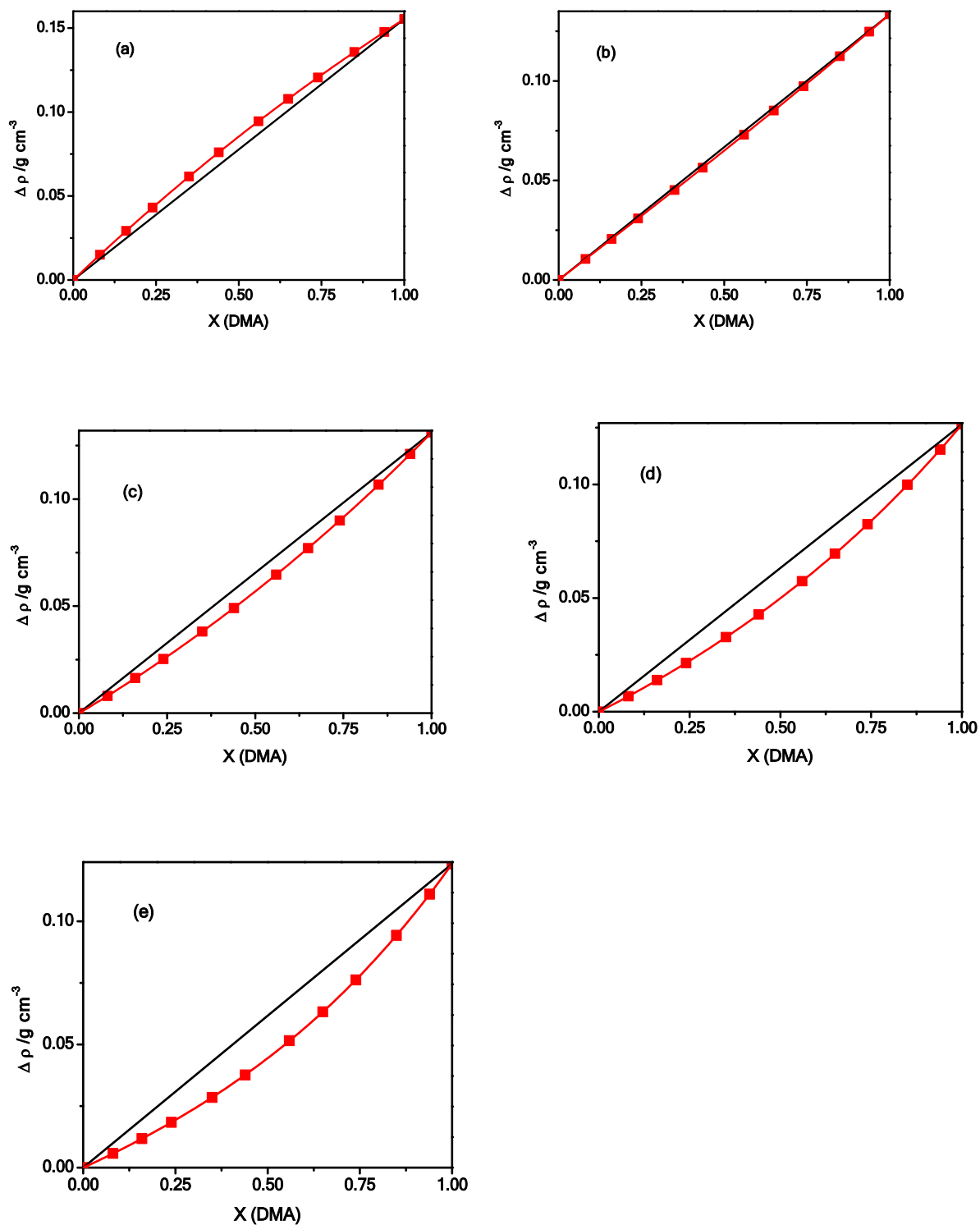

Figure S1 - Variations of densities for ROH/dimethylacetamide mixtures at $298.15 \mathrm{~K}$. $\mathrm{ROH}=$ 2-propanol (a), 2-butanol (b), 2-pentanol (c), 2-hexanol (d), 2-heptanol (e). Adapted from reference ${ }^{\mathrm{S} 1}$. 

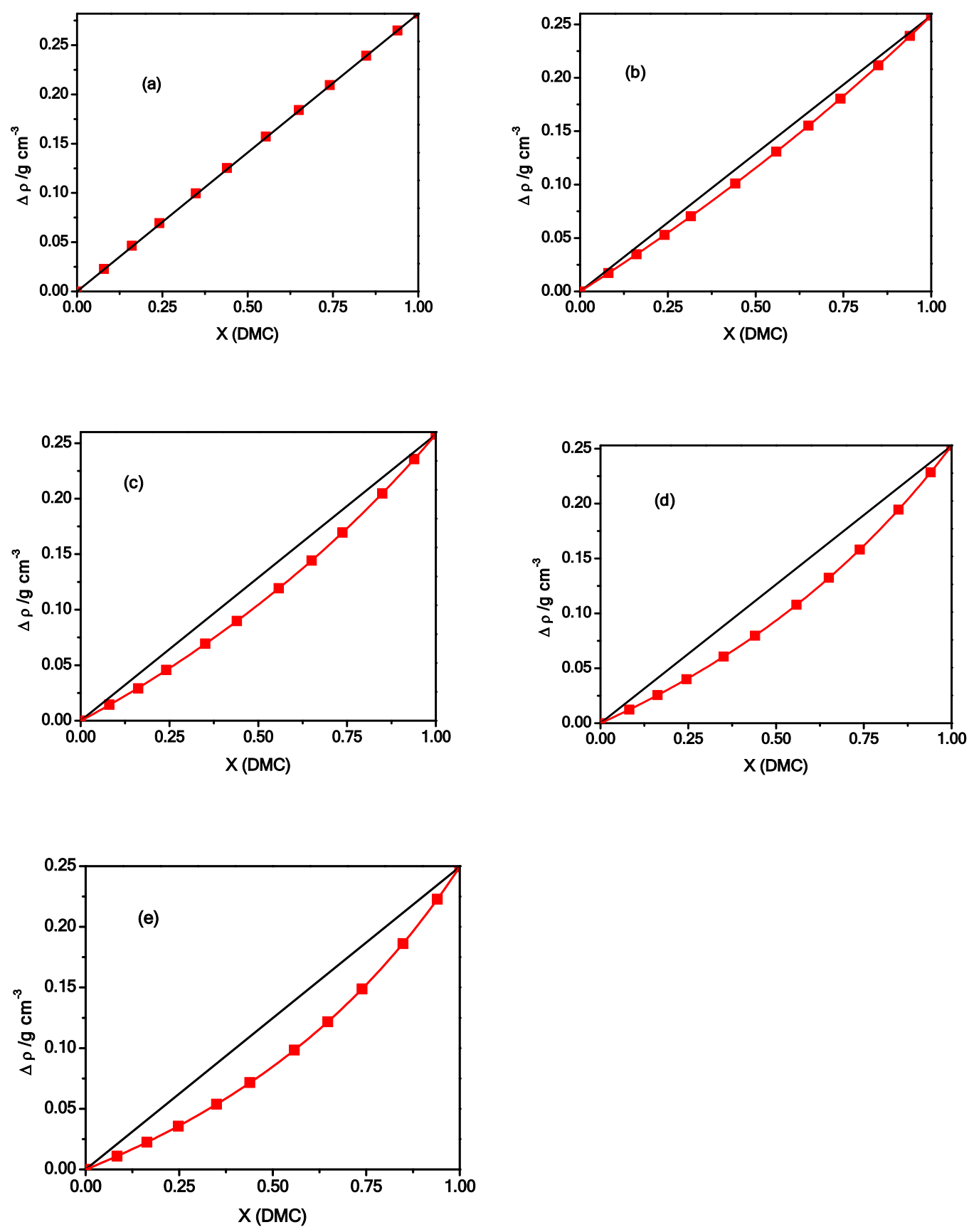

Figure S2 -Variations of densities for $\mathrm{ROH} /$ dimethylcarbonate mixtures at $298.15 \mathrm{~K}$.

$\mathrm{ROH}=$ 2-propanol (a), 2-butanol (b), 2-pentanol (c), 2-hexanol (d), 2-heptanol (e). Adapted from reference ${ }^{\mathrm{S} 2}$. 

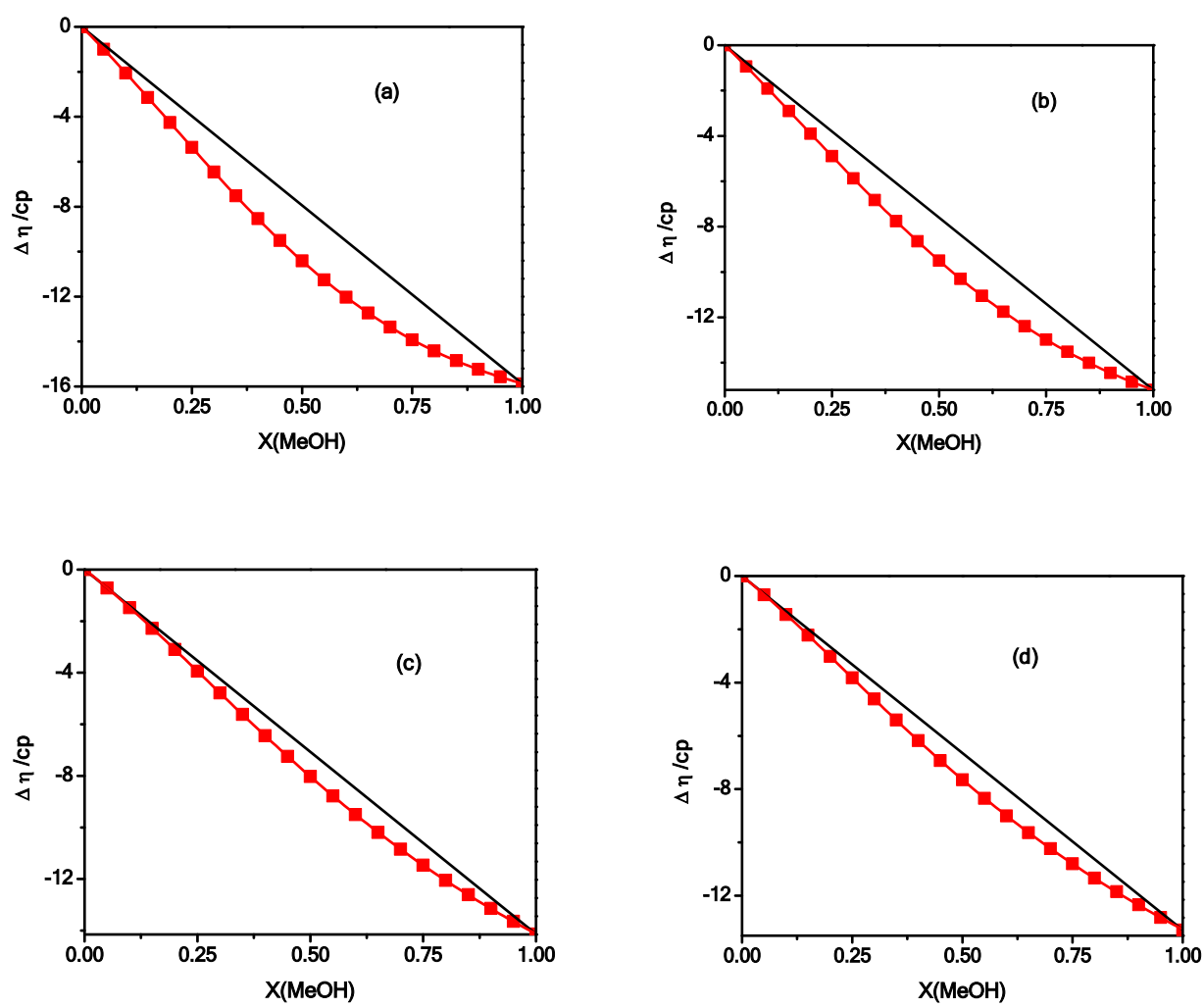

Figure S3 - Variations of viscosities of 1-decanol/ROH mixtures at $15^{\circ} \mathrm{C}$. $\mathrm{ROH}=$ methanol (a), ethanol (b), 1-propanol (c), 1-butanol (d).

Adapted from reference ${ }^{\mathrm{S} 3}$. 

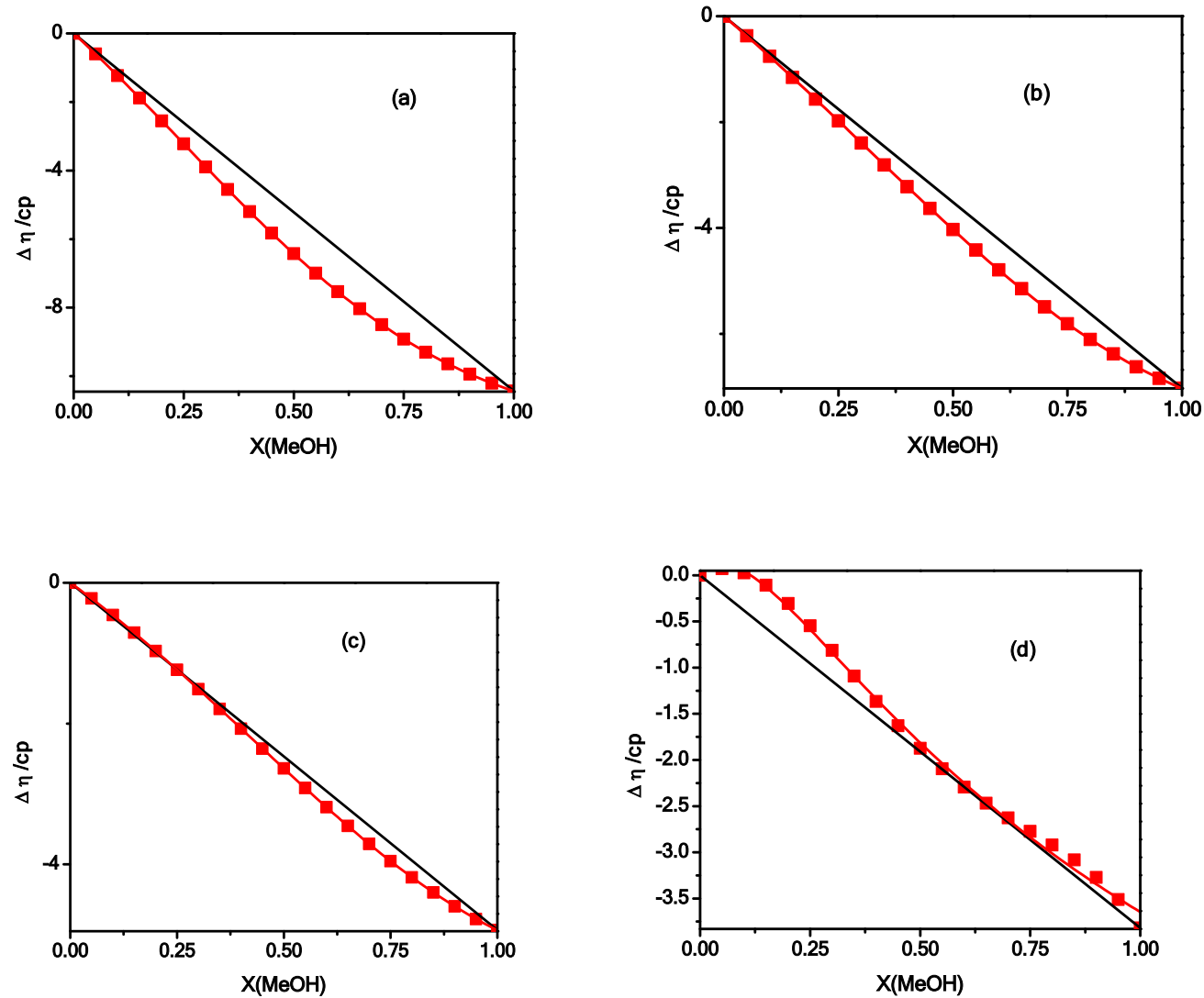

Figure S4 - Variations of viscosities of 1-decanol/methanol mixtures at $25^{\circ} \mathrm{C}$ (a) $35^{\circ} \mathrm{C},(\mathrm{b}), 45^{\circ} \mathrm{C}(\mathrm{c}), 55^{\circ} \mathrm{C}(\mathrm{d})$. Adapted from reference ${ }^{\mathrm{S} 3}$. 

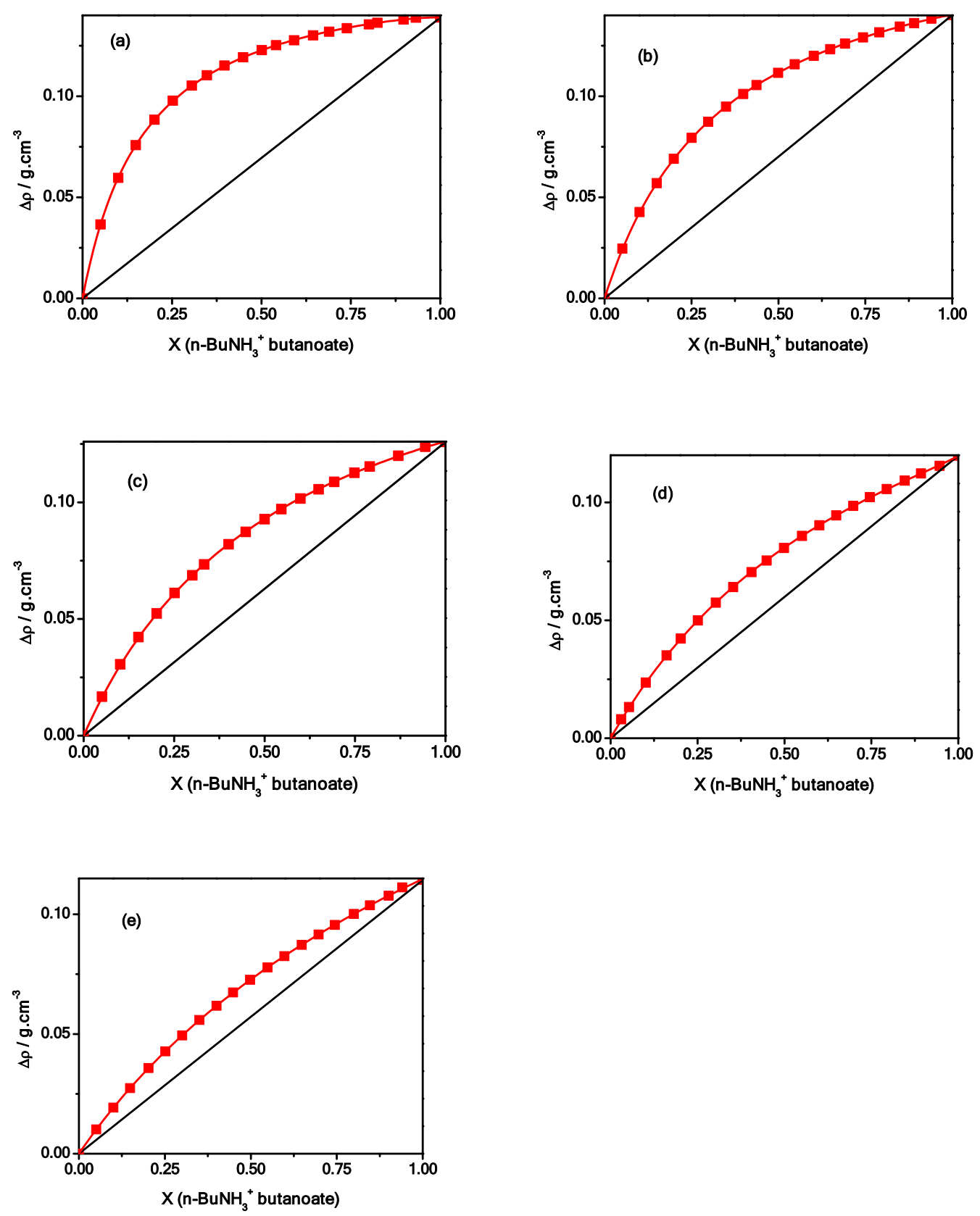

Figure S5 - Variations of densities of $\mathrm{ROH} / \mathrm{n}$-Butylammonium butanoate (BAB) mixtures at $298.15 \mathrm{~K} . \mathrm{ROH}=$ methanol (a), ethanol (b), 1-propanol (c), 1-butanol (d), 1-pentanol (e). Adapted from reference ${ }^{\mathrm{S}}$. 

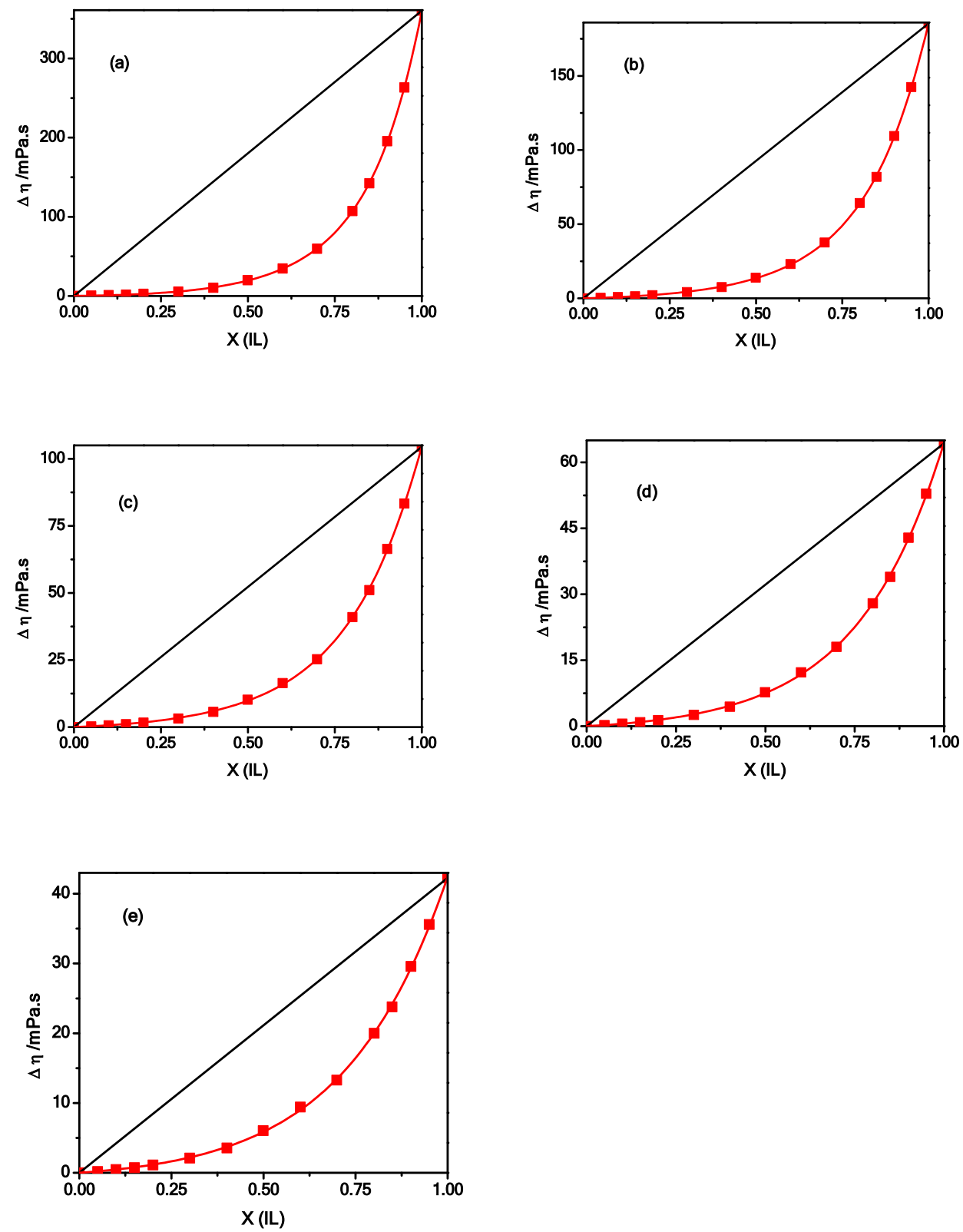

Figure S6 - Variations of viscosities of Methanol/[Bmim] $\mathrm{BF}_{4}$ mixtures at $278.15 \mathrm{~K}$ (a); $288.15 \mathrm{~K}$ (b); $298.15 \mathrm{~K}$ (c), $308.15 \mathrm{~K}$ (d), 318.15 K (e). Adapted from reference $\mathrm{s5}$. 

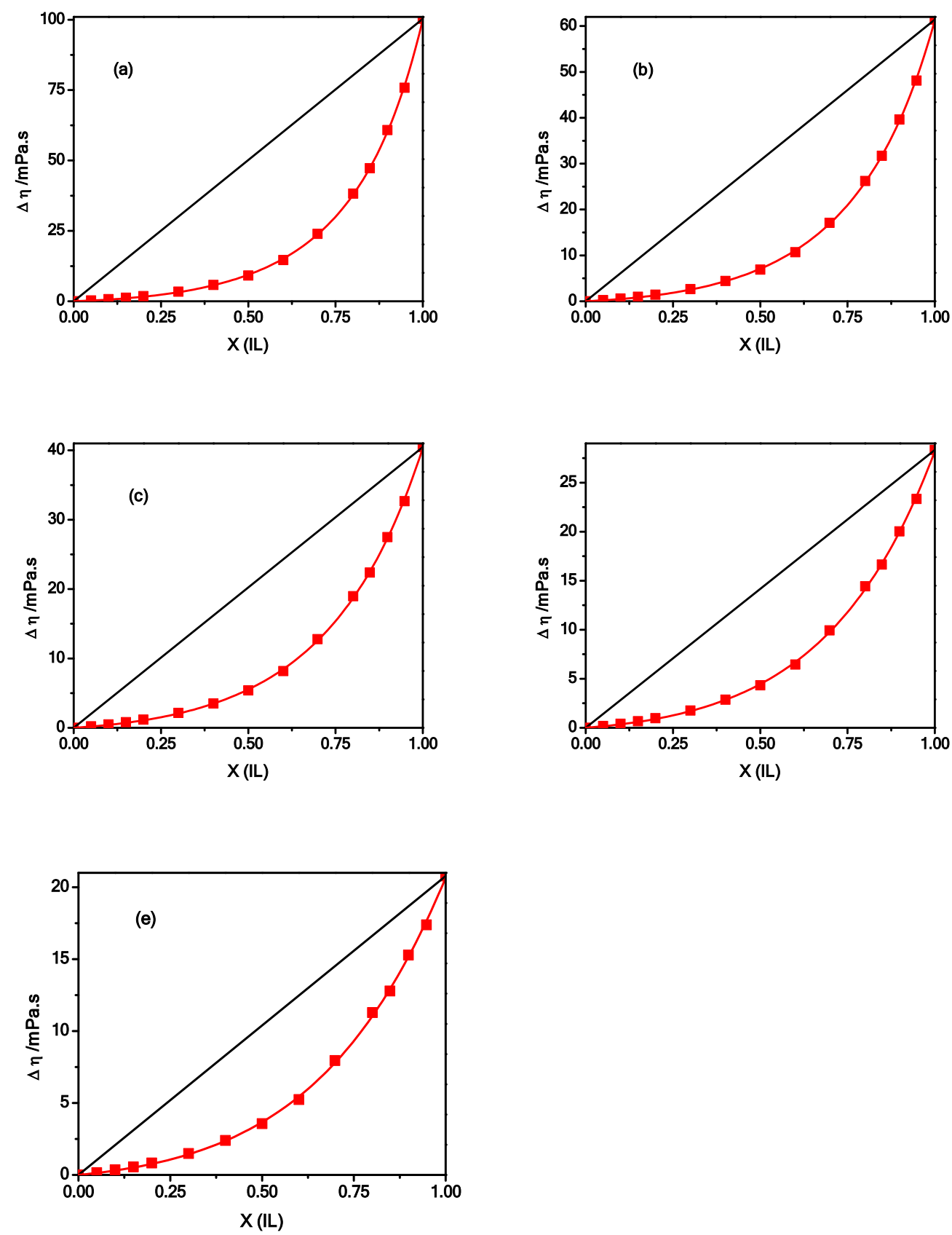

Figure S7 - Variations of viscosities of Methanol/[Emim]BF 4 mixtures at $278.15 \mathrm{~K}$ (a); $288.15 \mathrm{~K}$ (b); $298.15 \mathrm{~K}$ (c), 308.15 K (d), 318.15 K (e). Adapted from reference ${ }^{\mathrm{S} 5}$. 

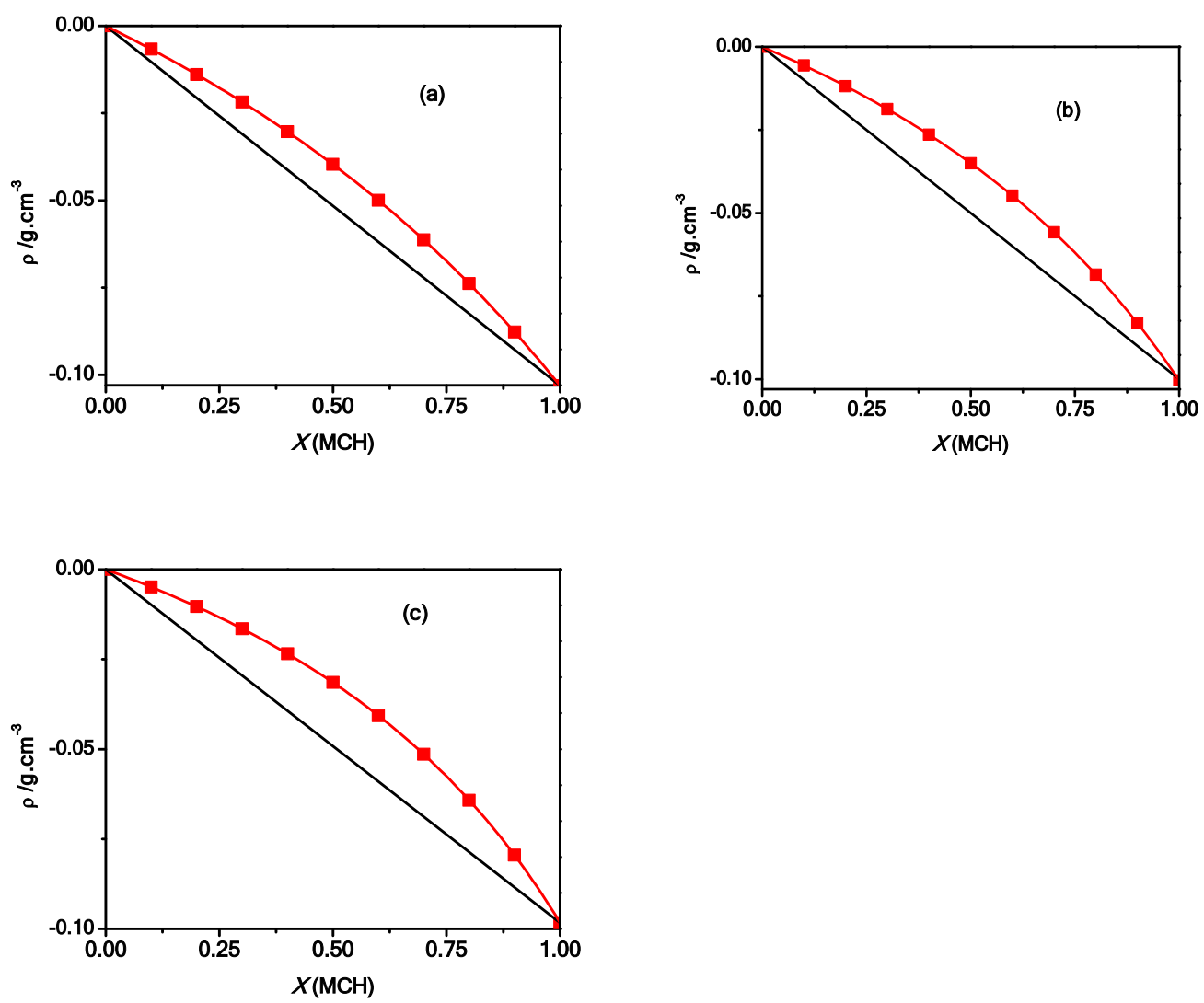

Figure S8 - Variations of densities of mixtures of fatty acid esters + methylcyclohexane (MCH) at 298.15 K. (a) Methyl decanoate / MCH; (b) methyl dodecanoate/MCH; (c) methyl tetradecanoate/MCH. Adapted from reference ${ }^{\mathrm{S} 6}$. 

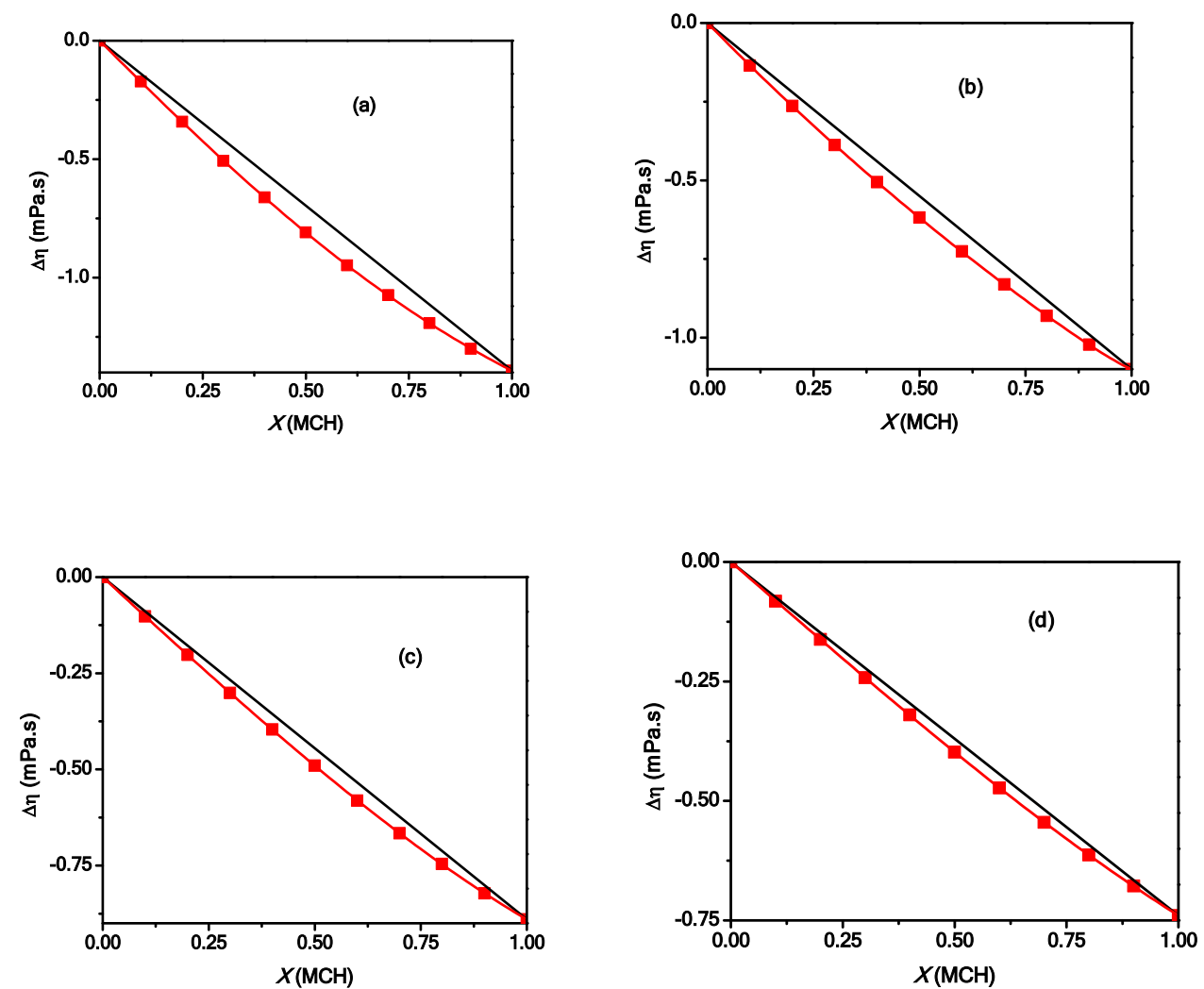

Figure S9 - Variations of viscosities of methyl decanoate/methylcyclohexane mixtures at increasing temperatures. (a) $293.15 \mathrm{~K}$; (b) $303.15 \mathrm{~K}$; (c) $313.15 \mathrm{~K}$; (d) $323.15 \mathrm{~K}$. Adapted from reference ${ }^{\mathrm{S} 6}$. 

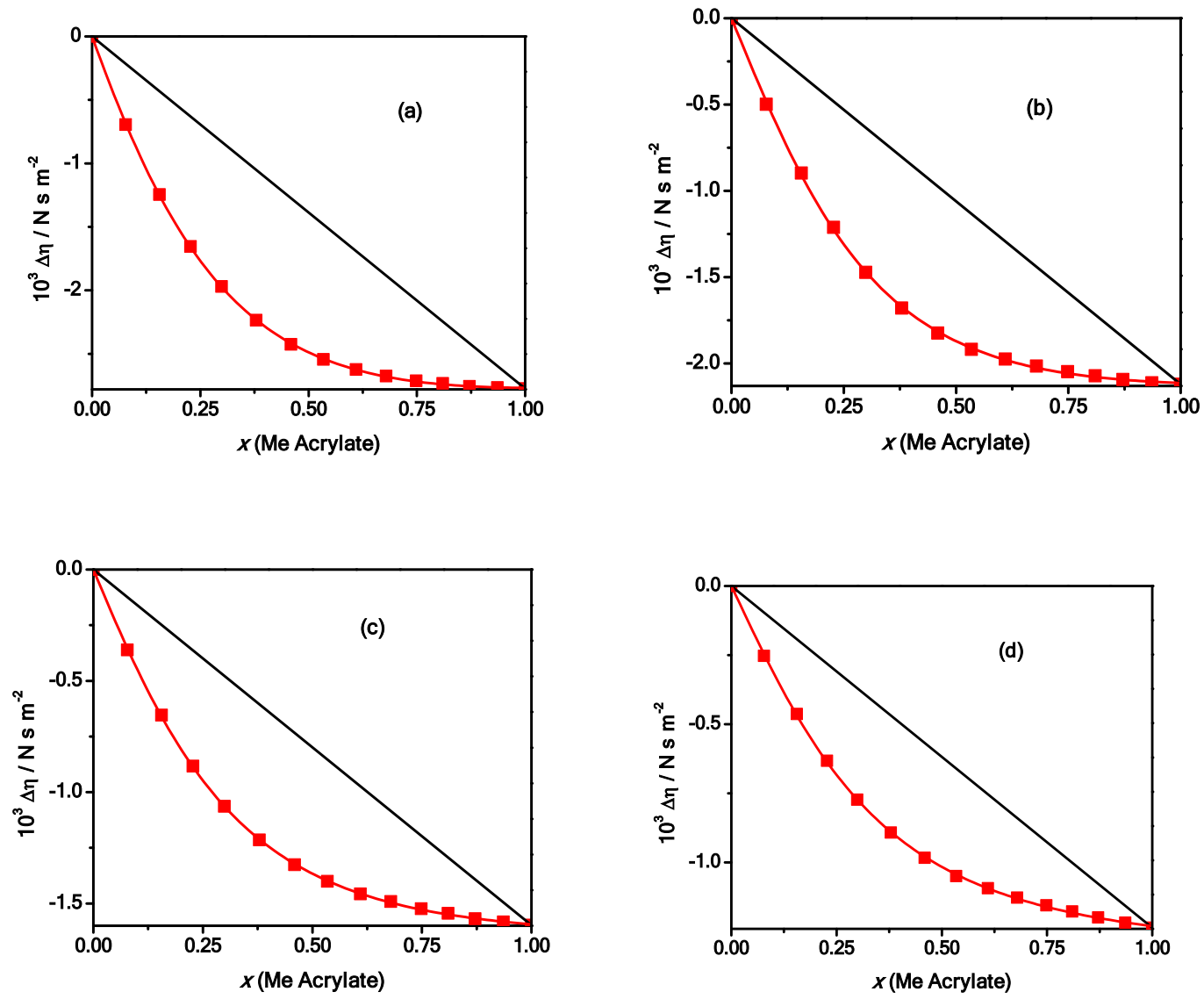

Figure S10 - Variations of viscosity of 1-BuOH/Methyl acrylate mixtures at increasing temperatures. (a) $288.15 \mathrm{~K}$; (b) $298.15 \mathrm{~K}$; (c) $308.15 \mathrm{~K}$; (d) $318.15 \mathrm{~K}$. Adapted from reference ${ }^{\mathrm{S} 7}$. 

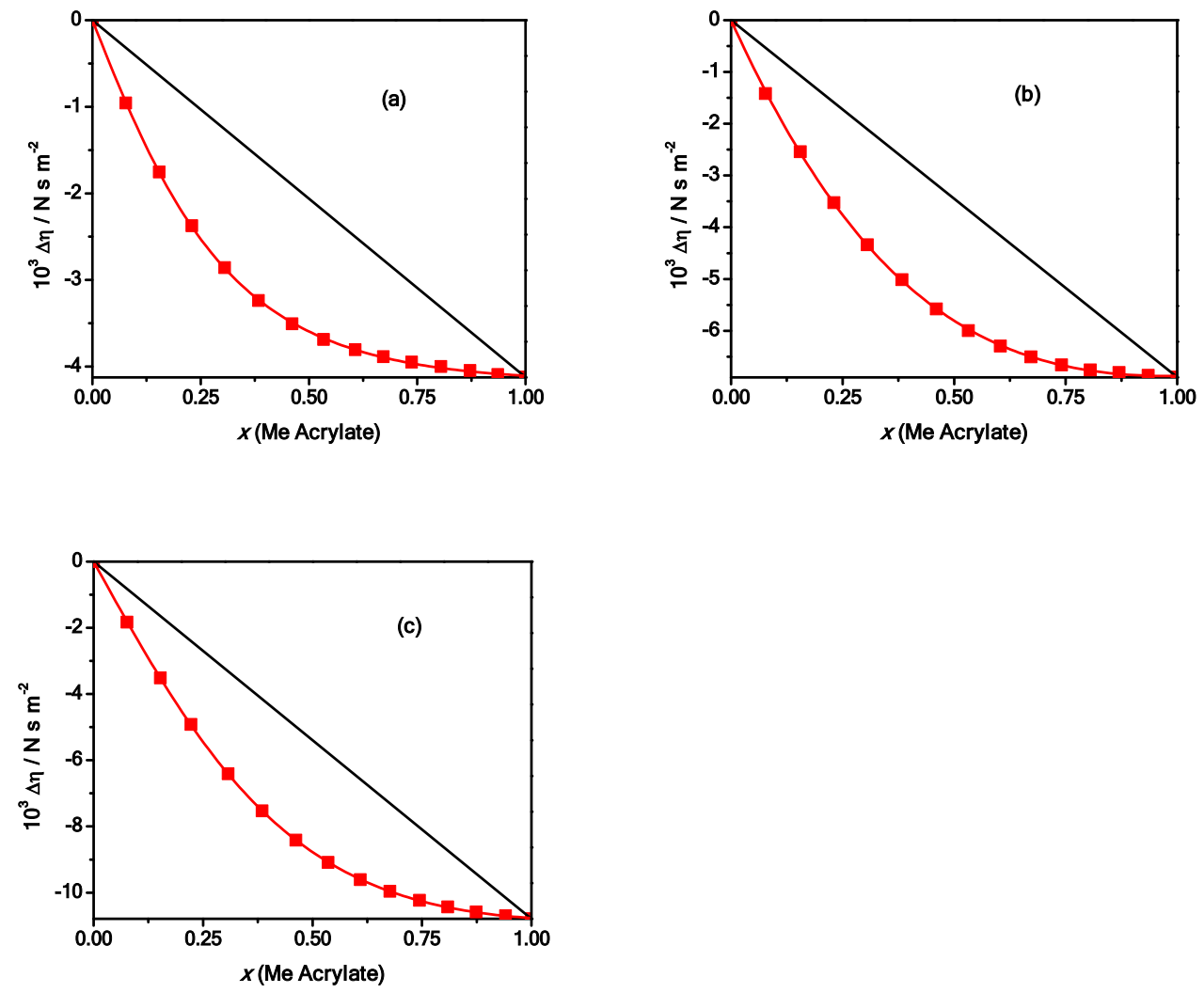

Figure S11 - Variations of viscosity of 1-alkanol/methyl acrylate mixtures at $298.15 \mathrm{~K}$. (a) 1-hexanol/methyl acrylate; (b) 1-octanol/methyl acrylate; (c) 1-decanol/methyl acrylate. Adapted from reference $\mathrm{S}$. 

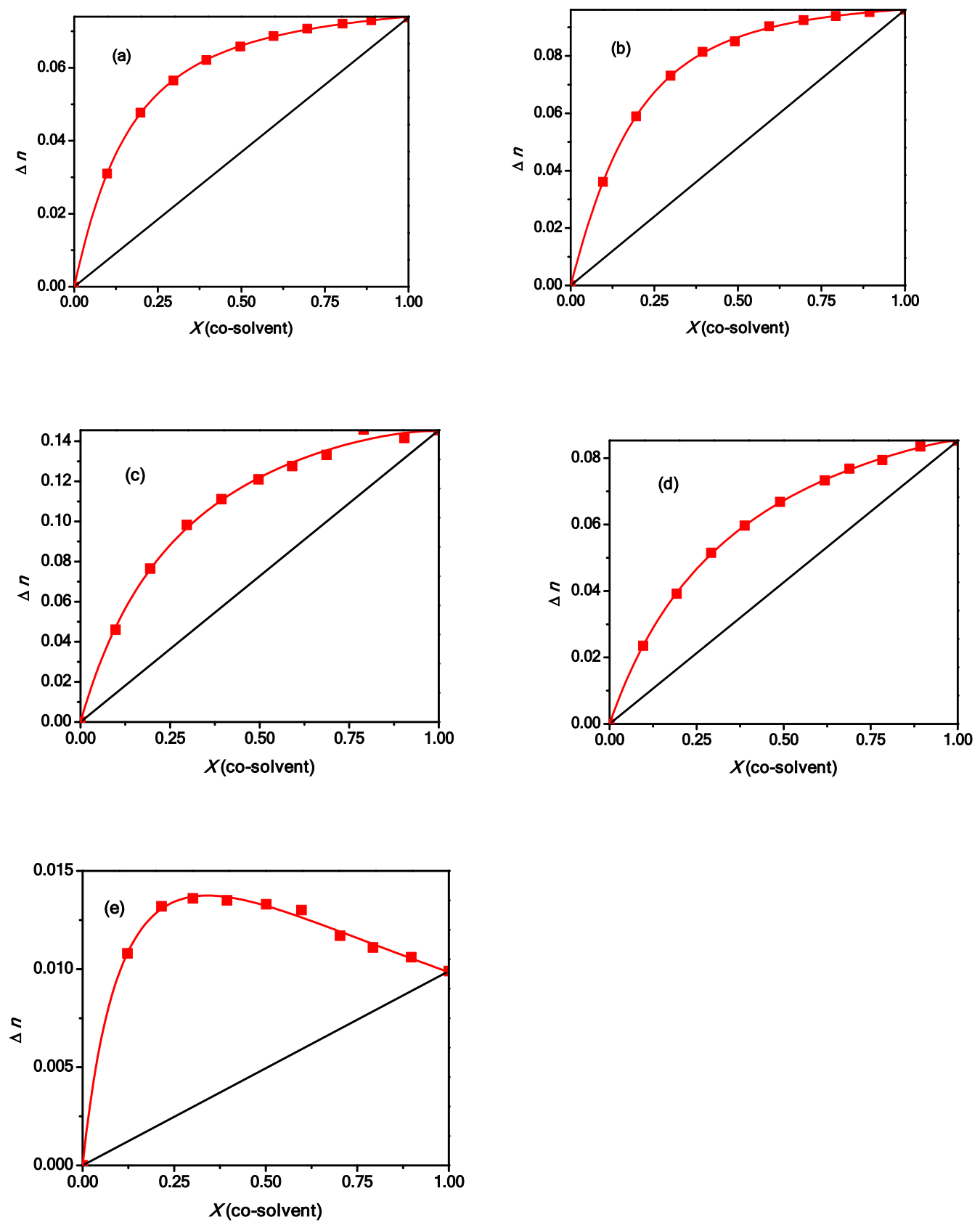

Figure S12 - Deviations of the refractive index at $298.15 \mathrm{~K}$ of aqueous solutions of organic solvents. (a) $\mathrm{H}_{2} \mathrm{O} / \mathrm{THF}$; (b) $\mathrm{H}_{2} \mathrm{O} / \mathrm{DMF}$; (c) $\mathrm{H}_{2} \mathrm{O} / \mathrm{DMSO}$; $\mathrm{H}_{2} \mathrm{O}$ /Ethyleneglycol; (e) $\mathrm{H}_{2} \mathrm{O}$ /acetonitrile. Adapted from reference ${ }^{\mathrm{S} 8}$. 
Fitting equation and parameters for excess properties

Experimental data of plots of Figures S13-S17 were fitted with equation (2). Fitting parameters A, B,C and D are given in Table S2, together with the corresponding squared correlation coefficients.

$$
\text { Excess Property }=\left[\mathrm{AX}_{2}{ }^{2}+\mathrm{B}\left(1-\mathrm{X}_{2}\right) \mathrm{X}_{2}\right] /\left[\left(1-\mathrm{X}_{2}\right)^{2}+\mathrm{C} \mathrm{X}_{2}{ }^{2}+\mathrm{D}\left(1-\mathrm{X}_{2}\right) \mathrm{X}_{2}\right]
$$

Table S2 - Parameters and correlation coefficients, according to Equation (2), for the fitting curves drawn in Figures S13-S17

\begin{tabular}{|c|c|c|c|c|c|c|}
\hline Figure & A & B & $\mathrm{C}$ & D & $\begin{array}{l}N \text { (Data } \\
\text { points) }\end{array}$ & $R^{2}$ \\
\hline S13a & -2.64 & 3167 & 1.07 & 3.32 & 13 & 1 \\
\hline S13b & -7.73 & 4702.45 & 1.2 & 3.48 & 16 & 1 \\
\hline S13c & -3.46 & 5988.94 & 1.16 & 3.71 & 13 & 1 \\
\hline S13d & -7.33 & 6401.46 & 0.93 & 3.59 & 14 & 1 \\
\hline S13e & -5.35 & 7415.44 & 1.1 & 4.07 & 13 & 1 \\
\hline S13f & 8.92 & 8263.73 & 0.98 & 4.62 & 18 & 1 \\
\hline S13g & 4.68 & 9889.16 & 1.66 & 6.04 & 9 & 1 \\
\hline S13h & 0.11 & 7935.67 & 1.05 & 4.55 & 12 & 1 \\
\hline S14a & -10.81 & 4357.67 & 1.04 & 2.7 & 16 & 1 \\
\hline S14b & -8.28 & 5938.09 & 1.13 & 3.69 & 15 & 1 \\
\hline S14c & -11.43 & 5766.1 & 0.95 & 2.82 & 16 & 1 \\
\hline S14d & 3.9 & 7925.26 & 0.97 & 4.22 & 11 & 1 \\
\hline S14e & -48.85 & 4371.98 & 14.11 & 7.57 & 10 & 0.99 \\
\hline S14f & -6.81 & -14633.9 & 2.74 & 1.63 & 14 & 1 \\
\hline S14g & -3.15 & -16019.3 & 1.4 & 1.79 & 12 & 1 \\
\hline S15a & 0.24 & -6.11 & 5.13 & 2.06 & 23 & 0.99 \\
\hline S15b & 0.24 & -5.4 & 5.47 & 1.59 & 21 & 0.99 \\
\hline S15c & 0.4 & -2.92 & 5.28 & -0.43 & 21 & 0.97 \\
\hline S15d & 0.87 & -3.97 & 10.02 & 1.32 & 21 & 0.95 \\
\hline S16a & -1.22 & -2214 & 8.05 & 8.15 & 23 & 1 \\
\hline S16b & -4.8 & -1366 & 6.14 & 7.14 & 21 & 1 \\
\hline S16c & -3.81 & -829.5 & 4.9 & 5.74 & 19 & 1 \\
\hline S16d & -1.31 & -5.78 & 4.41 & 5.47 & 19 & 1 \\
\hline S17a & -0.04 & -6.29 & 1.66 & 3.15 & 38 & 0.999 \\
\hline S17b & 0.016 & -2.38 & 3.18 & 3.1 & 34 & 0.999 \\
\hline S17c & 0.0017 & -1.6 & 2.05 & 1.71 & 37 & 0.999 \\
\hline S17d & -0.02 & -4.23 & 3.08 & 2.53 & 37 & 0.999 \\
\hline S17e & -0.067 & -6.66 & 5.33 & 3.36 & 32 & 0.998 \\
\hline S17f & -0.1 & -10.28 & 7.55 & 4.69 & 34 & 0.998 \\
\hline S17g & -0.25 & -19.1 & 12.89 & 8.42 & 32 & 0.997 \\
\hline S17h & -0.48 & -27.44 & 17.84 & 11.71 & 30 & 0.996 \\
\hline S17i & -1.6 & -45.7 & 27.74 & 19.54 & 29 & 0.994 \\
\hline
\end{tabular}




\section{Plots for the calculation of NIA values}

All plots are original, and were drawn with fitting equation (2) and parameters listed in Table S2.
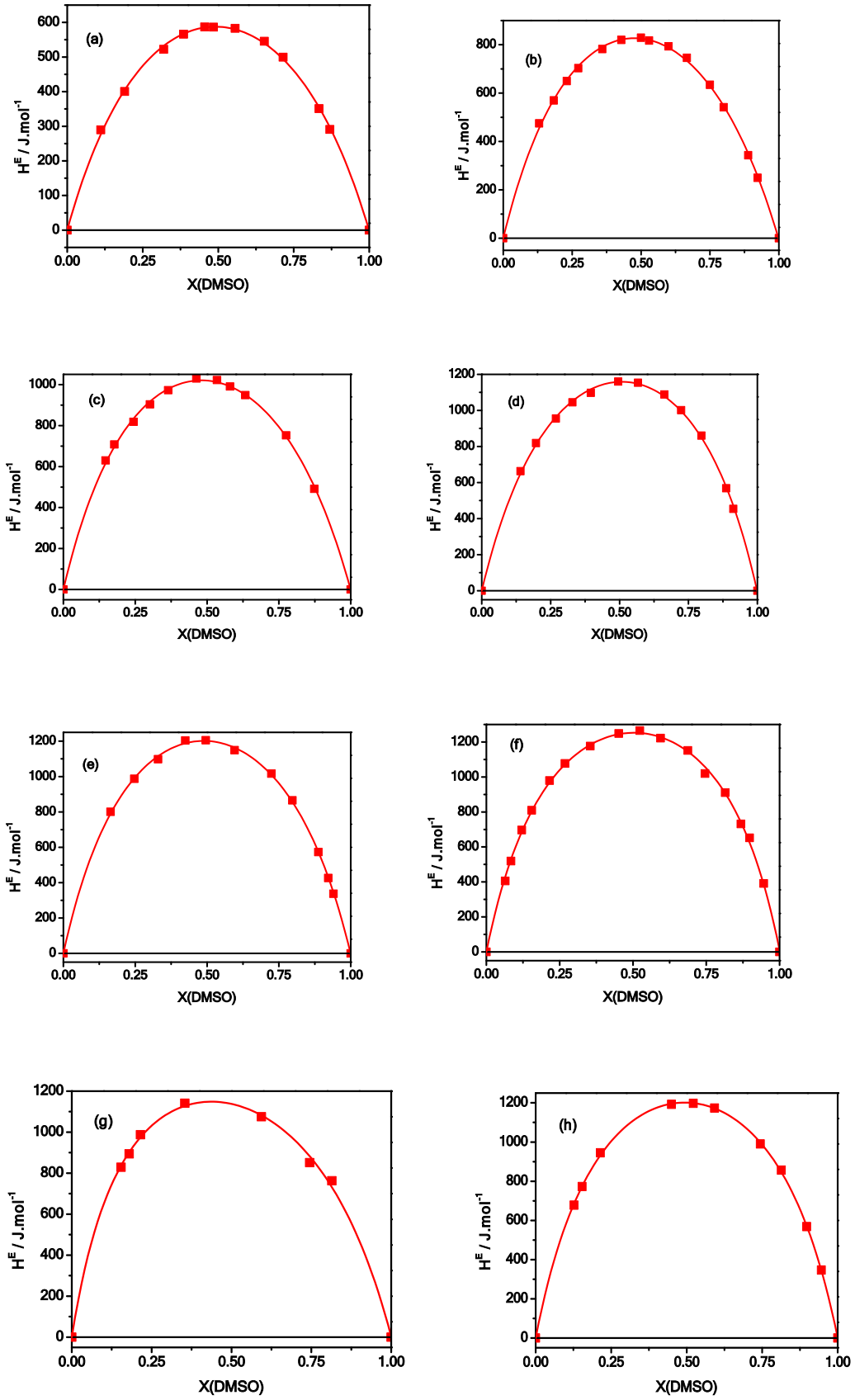

Figure S13 - Variations of excess enthalpies of arenes/dimethylsulfoxide mixtures at 298.15 K. Arene = benzene (a), toluene (b), ethylbenzene (c), 1-propylbenzene (d), 2propylbenzene (e), 1-butylbenzene (f), sec-butylbenzene (g), ter-butylbenzene (h). Adapted from reference ${ }^{\mathrm{S}}$. 

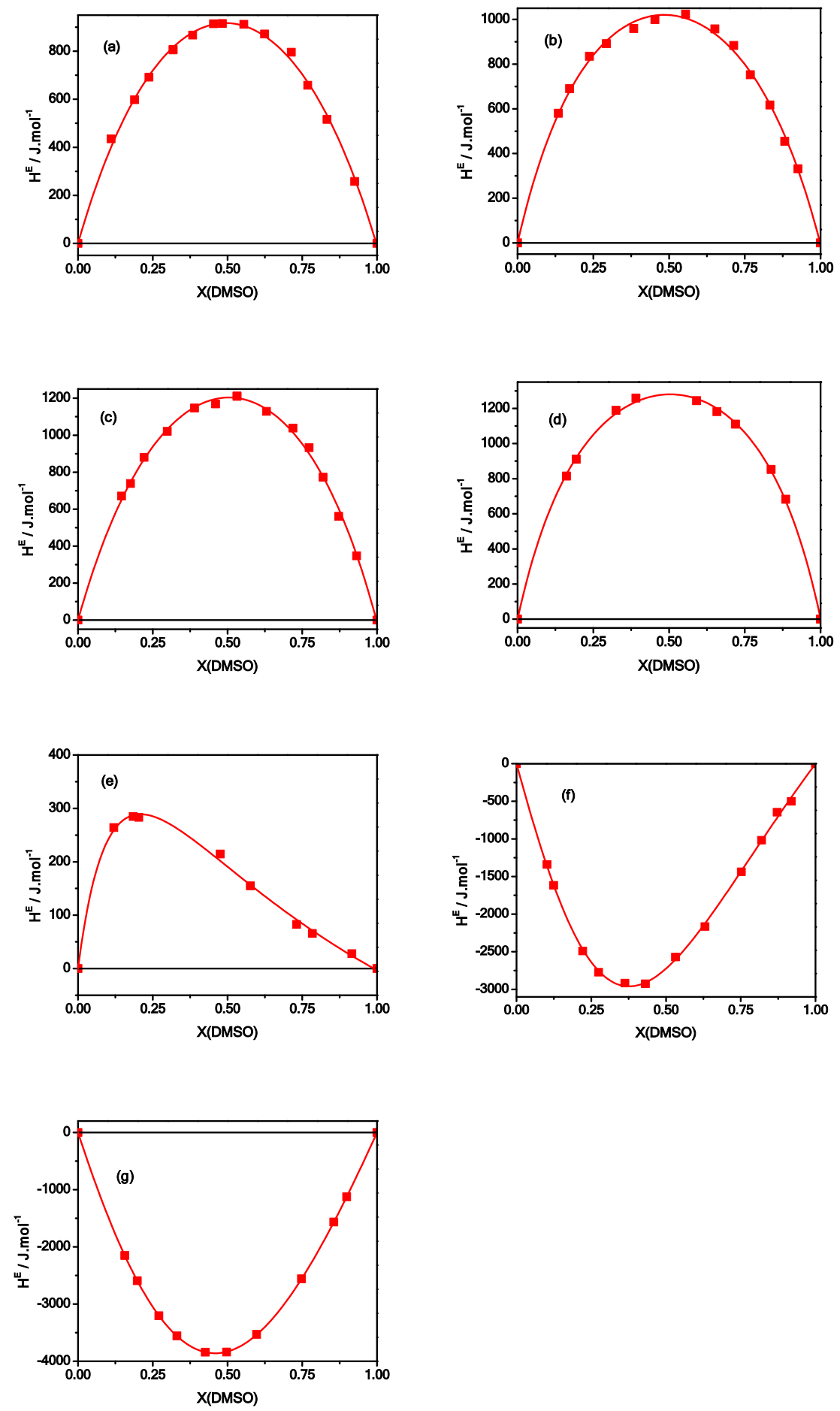

Figure S14 - Variations of excess enthalpies of polyhaloalkanes/dimethylsulfoxide mixtures at 298.15 K. Polyhaloalkane = 1-chloropropane (a), 1-chlorobutane (b), 1chloropentane (c), 1-chlorohexane (d), tetrachloromethane (e), trichloromethane (f), 1,1,2,2-tetrachloroethane (g). Adapted from reference ${ }^{\mathrm{S} 9}$. 

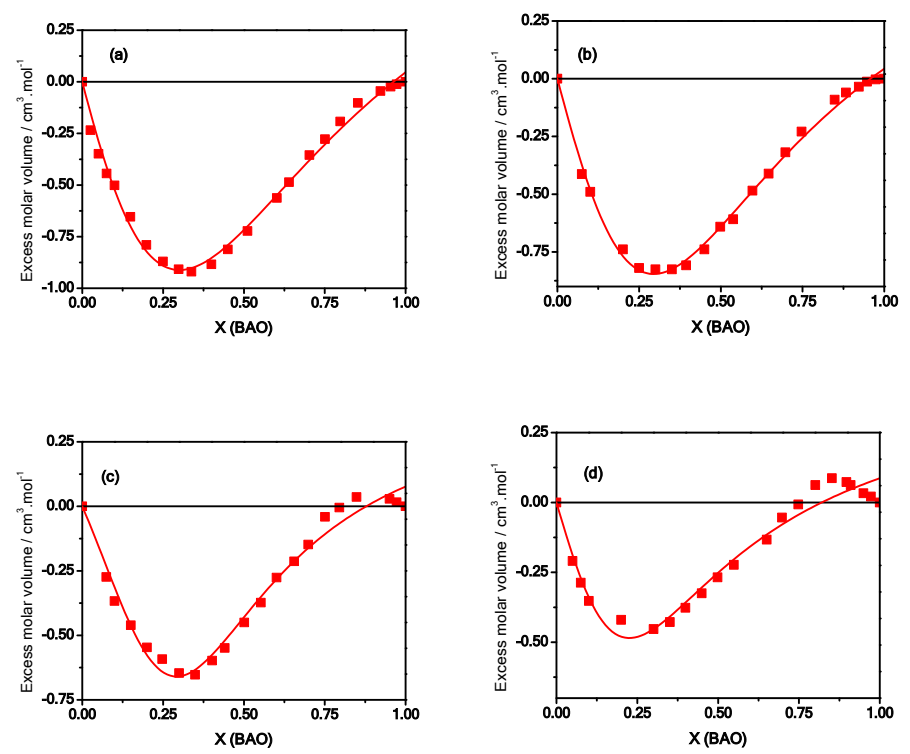

Figure S15 - Variations of excess molar volumes of ROH/n-butylammonium oleate (BAO) mixtures at 298.15 K ROH = 1-propanol (a), 1-butanol (b), 1-pentanol (c), 1hexanol (d). Adapted from reference ${ }^{\text {s10. }}$.
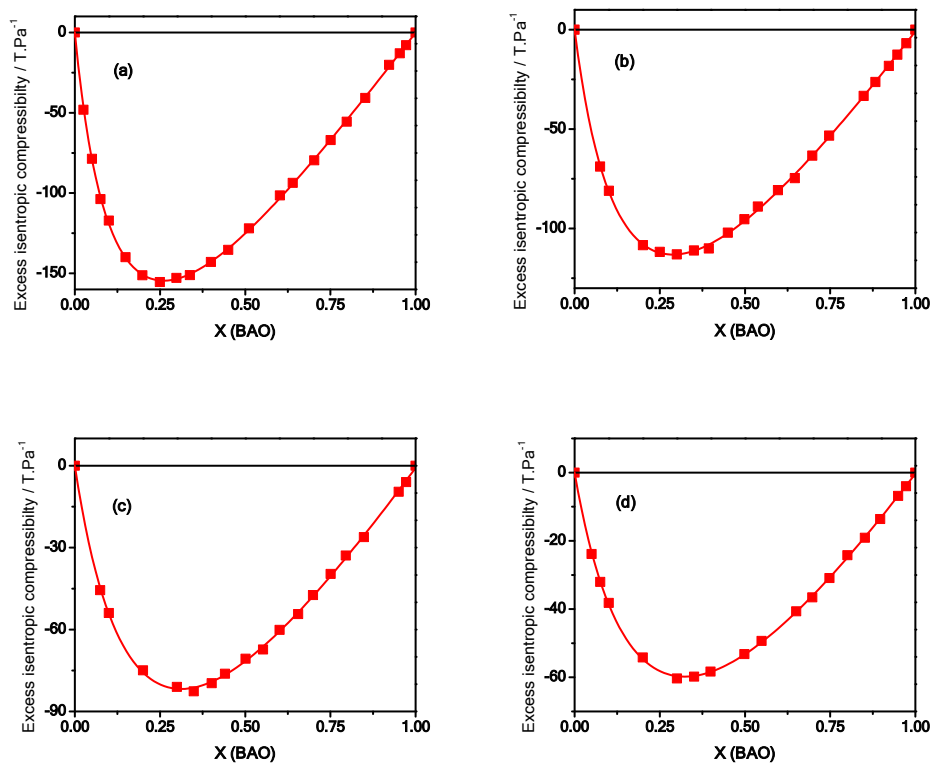

Figure S16 - Variations of isentropic compressibilities of $\mathrm{ROH} / \mathrm{n}$-butylammonium oleate $(\mathrm{BAO})$ mixtures at $298.15 \mathrm{~K} . \mathrm{ROH}=1$-propanol (a), 1-butanol (b), 1-pentanol (c), 1-hexanol (d). Adapted from reference ${ }^{\mathrm{S} 10}$. 

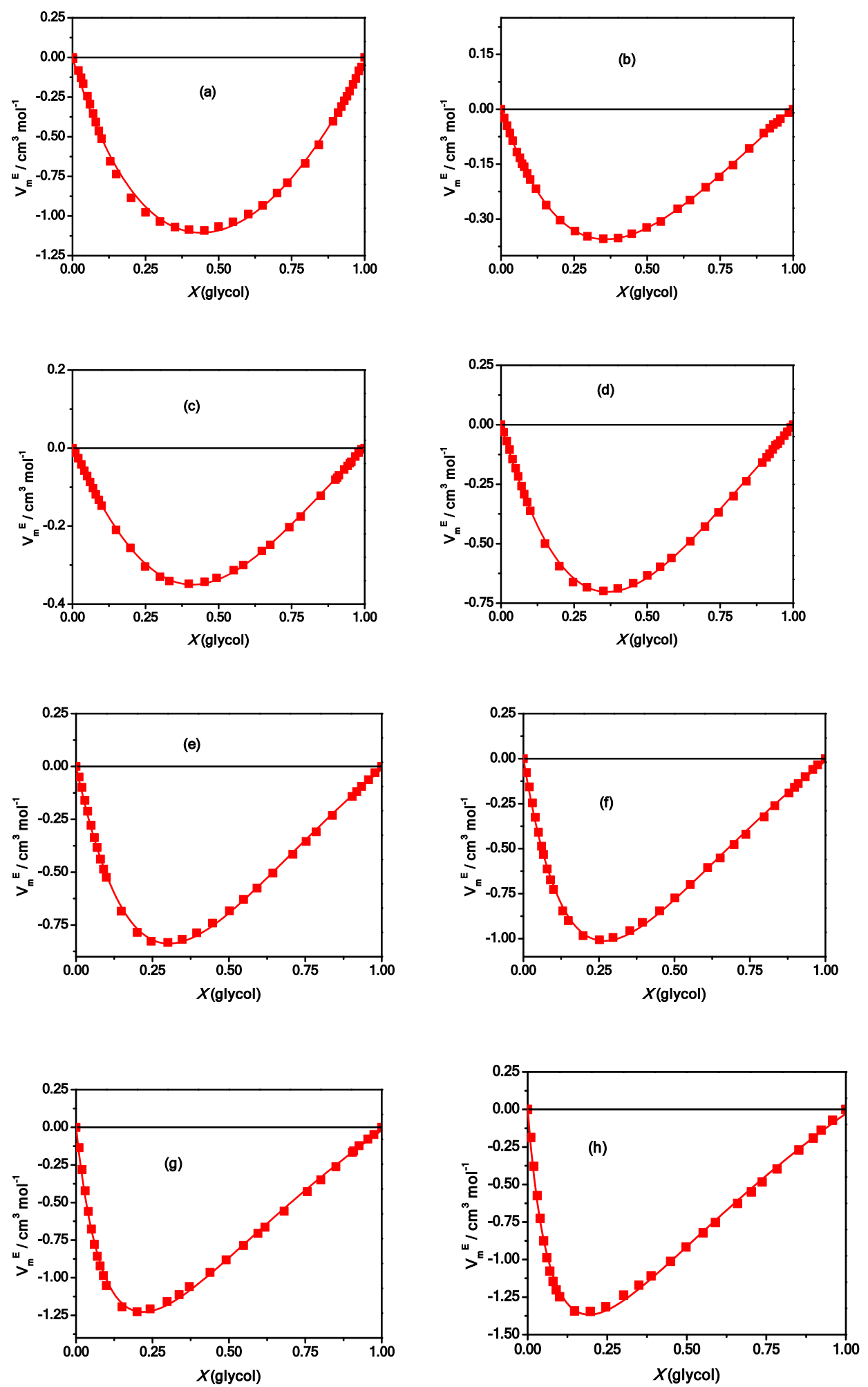


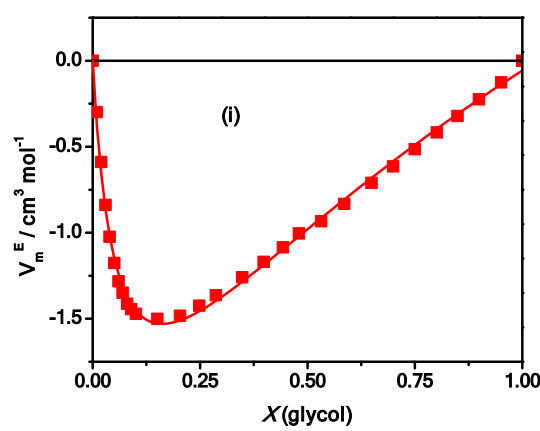

Figure S17 - Variations of excess molar volumes of water/alcohols and water/polyethyleneglycol (PEG) mixtures at 298.15 K. (a) $\mathrm{H}_{2} \mathrm{O} / \mathrm{EtOH}$; (b) $\mathrm{H}_{2} \mathrm{O}$ /Glycerol; (c) $\mathrm{H}_{2} \mathrm{O} /$ Ethyleneglycol; (d) $\mathrm{H}_{2} \mathrm{O}$ /Diethyleneglycol; (e) $\mathrm{H}_{2} \mathrm{O}$ /Triethyleneglycol; (f) $\mathrm{H}_{2} \mathrm{O} / \mathrm{PEG} 200$; (g) $\mathrm{H}_{2} \mathrm{O} / \mathrm{PEG} 300$; (h) $\mathrm{H}_{2} \mathrm{O} / \mathrm{PEG} 400$; (i) $\mathrm{H}_{2} \mathrm{O} /$ PEG600. Adapted from reference ${ }^{\mathrm{S} 11}$. 


\section{Detailed procedure for calculating NII or NIA values}

NII and NIA values were obtained graphically with the aid of software ORIGINPRO 9.0 .

NII values were obtained as the ratios $\mathrm{NII}=\mathrm{S} / \mathrm{S}_{\mathrm{ABC}}$ of the area $\mathrm{S}$ and the area $\mathrm{S}_{\mathrm{ABC}}$ of the triangle $\mathrm{ABC}$, as shown in the plots below, extracted from the above figures.

In Figures S18a, S is obtained by integrating the area under the fitting curve (red) between points $\mathrm{A}$ and $\mathrm{B}$, and subtracting from this value the area of triangle $\mathrm{ABC}$, which is half the product of $\mathrm{AB} \times \mathrm{BC}$. In Figure $\mathbf{S 1 8 b}, \mathrm{S}$ is obtained by integrating the area under the fitting curve (red) between points A and B, and subtracting this value from the area of triangle $A B C$, which is half the product of $A B \times B C$. A positive value is arbitrarily assigned to this ratio, if the plot indicates that the variation of the thermodynamic property is governed by the second component, added to the mixture (Figure S18a). The index assumes a negative value if the plot indicates that the variation of the thermodynamic property is governed by the first component of the mixture (Figure S18b).
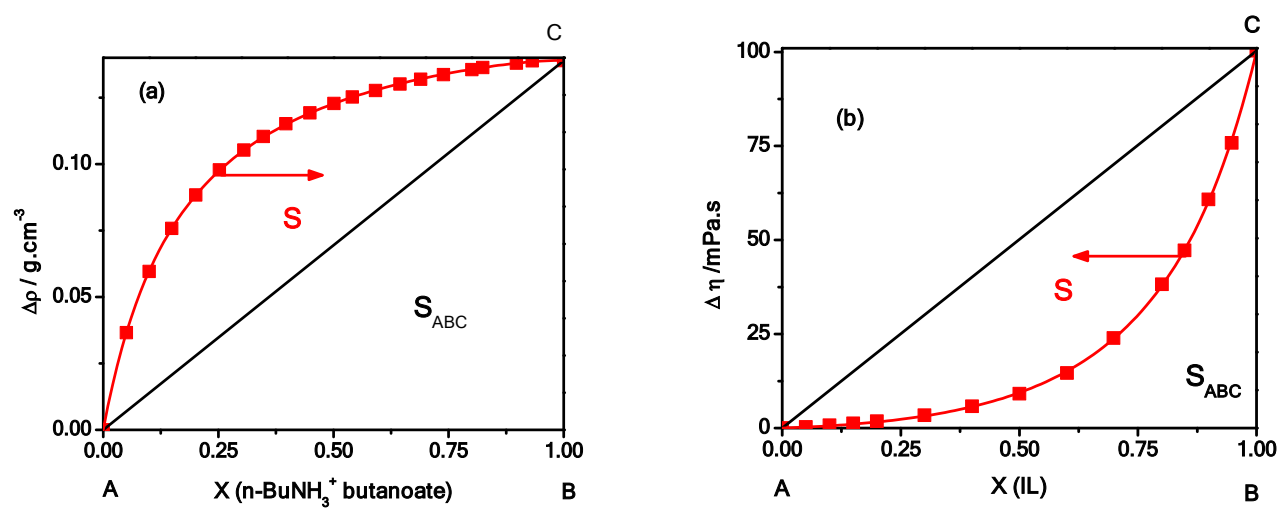

Figure S18 - Examples of experimental plots (Figs. S5a and S7a) from which the nonideality index is calculated as the ratio between areas $\mathrm{S}$ and $\mathrm{S}_{\mathrm{ABC}}$. A positive sign is attributed to the value if the plot indicates a variation governed by the second, added component of the mixture [plot (a)]. A negative sign is attributed to the value if the plot indicates that the variation is governed by the first component [plot (b)]. Arrows point to the component which governs the property variation. 
NIA values were obtained by integrating the areas $\mathrm{S}$ between points $\mathrm{A}$ and $\mathrm{B}$. Positive or negative signs were assigned to the value, if the deviations from the reference line were positive (FigureS19a) or negative (Figure S19b)
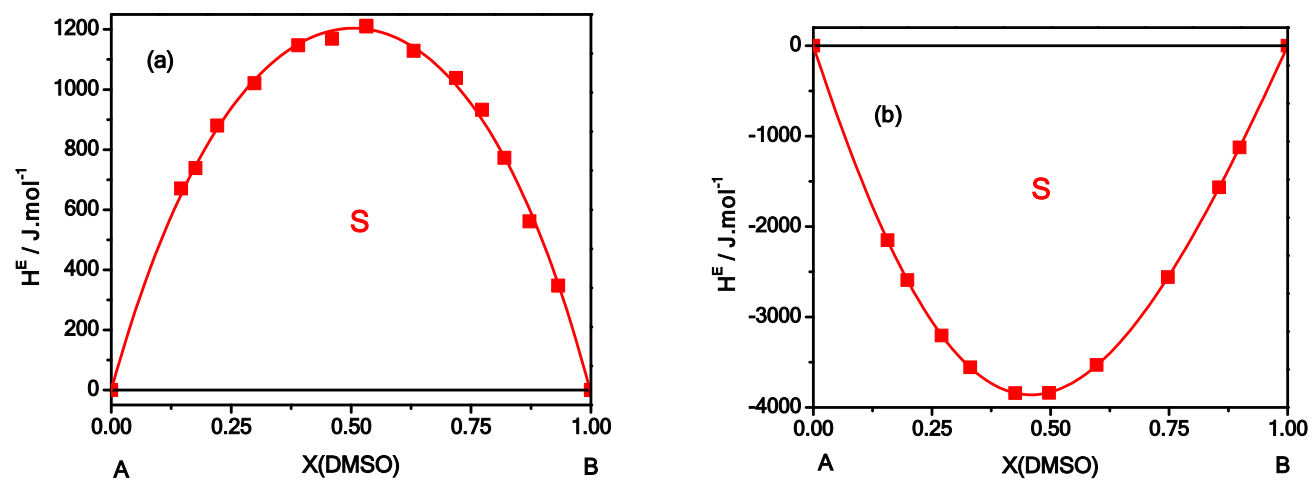

Figure S19 - Examples of experimental plots (Figs. S14c and S14g) from which the non-ideality area (NIA) is calculated as the integrated area S under the fitting curve, between points A and B. Plots (a) and (b) correspond to positive and negative NIA values, respectively.

\section{References}

(S1) Almasi, M. Thermodynamic properties of binary mixtures containing $N, N$ dimethylacetamide + 2-alkanol: experimental data and modeling. J. Chem. Eng. Data 2014, 59, 275-281.

(S2) Almasi, M. Thermodynamic properties of binary mixtures containing dimethyl carbonate +2 -alkanol: experimental data, correlation and prediction by ERAS model and cubic EOS. Physica B Condens. 2013, 412, 100-105. 
(S3) Rauf, M. A.; Stewart, G. H.; Farhataziz. Viscosities and densities of binary mixtures of 1-alkanols from $15{ }^{\circ} \mathrm{C}$ to $55^{\circ} \mathrm{C} . J$. Chem. Eng. Data 1983, 28, 324-328.

(S4) Bittencourt, S. S.; Hoga, H. E.; Torres, R. B.; d'Angelo, J. V. H. Thermodynamic properties of binary mixtures of $n$-butylammonium-based ionic liquids with ethanol at $T=(293.15-313.15)$ K. J. Therm. Anal. Calorim. 2019, $135,2519-2539$.

(S5) Vercher, E.; Llopis, F. J.; González-Alfaro, V.; Miguel, P. J.; Orchillés, V.; Martínez-Andreu, A. Volumetric properties, viscosities and refractive indices of binary liquid mixtures of tetrafluoroborate-based ionic liquids with methanol at several temperatures, J. Chem. Thermodynamics 2015, 90, 174-184

(S6) Li D., Guo M. Wang X., Lin Sh., Jia W., Wang G. Measurement and correlation of density and viscosity of binary mixtures of fatty acid (methyl esters + methylcyclohexane) J. Chem. Thermodynamics 2019, 137, 86-93.

(S7) Nain A.K., Droliva P., Gupta J. Deviations in viscosity and thermodynamics of viscous flow for binary mixtures of methyl acrylate with 1-alkanols at different temperatures. Indian J. Chem. 2018, 57A, 761-769.

(S8) Aminabhavi T.M. , Gopalakrishna B. Density, Viscosity, Refractive Index, and Speed of Sound in Aqueous Mixtures of N,N-Dimethylformamide, Dimethyl Sulfoxide, N,N-Dimethylacetamide, Acetonitrile, Ethylene Glycol, Diethylene Glycol, 1,4- Dioxane, Tetrahydrofuran, 2-Methoxyethanol, and 2-Ethoxyethanol at 298.15 K. J. Chem. Eng. Data 1995, 40, 856-861

(S9) Marongiu, B.; Piras, A.; Porcedda, S.; Tuveri, E. A comparative study of thermodynamic properties of binary mixtures containing dimethylsulfoxide. J. Therm. Anal. Calorim. 2007, 90, 909-922. 
(S10) Olivieri, G. V.; Cunha, C. S.; Martins, L. S.; Paegle, P. A. M.; Nuncio, S. D.; Morandim-Giannetti, A. A.; Torres, R. B. Thermodynamic and spectroscopic study of binary mixtures of $n$-butylammonium oleate ionic liquid + alcohol at $\mathrm{T}=288.15-$ 308.15 K. J. Therm. Anal. Calorim. 2018, 131, 2925-2942

(S11) Hoga H.E., Torres R.B., Volpe P.L.O., Thermodynamics properties of binary mixtures of aqueous solutions of glycols at several temperatures and atmospheric pressure, J.Chem.Thermodynamics 2018, 122, 38-64. 